W.A. Tweed MD FRCPC,

T.L. Lee MBBS FFARACS MMed(Anacs)

\title{
Time-cycled inverse ratio ventilation does not improve gas exchange during anaesthesia
}

Inverse ratio ventilation (IRV) has been reported to improve oxygenation at lower peak airway pressures in patients with respiratory failure. Therefore we hypothesised that IRV might also improve oxygen exchange during anaesthesia. Conventional ratio ventilation (CRV) and IRV were compared in 24 low-risk surgical patients who were paralysed and whose lungs were ventilated with air $\mathrm{O}_{2}$ by a non-rebreathing circuit and a Siemens 900.C servo ventilator. Two levels of time-cycled IRV (I:E ratios of 60/40 and 77/23) were bracketed by control periods with CRV (I E ratio of 35/65). Inspired $\mathrm{O}_{2}$ fraction, $\mathrm{O}_{2}$ uptake and $\mathrm{CO}_{2}$ elimination, arterial blood gases, pulmonary ventilation and mechanic's, heart rate and blood pressure were measured. From these data alveolar and dead space ventilation and four oxygen tension-based indices of gas exchange were calculated. During $I R V$, mean airway pressure (mean AWP) was increased but there were no changes in oxygen exchange indices, pulmonary mechanics, HR or BP. A sub-set of the sample with moderately impaired oxygen exchange, defined as the upper quartile for $(A-a) \mathrm{DO}_{2}$, was examined separately with identical results. Multivariate models were tested to identify variables which predicted $\mathrm{O}_{2}$ exchange during $\mathrm{CRV}$. Patient age was the only predictor consistently significant in all models. We conclude that age is an important determinant of impaired pulmonary oxygen exchange during anaesthesia, and that increasing mean AWP by TC-IRV has no beneficial effects on pulmonary mechanics or gas exchange.

\section{Key words}

LUNG: gas exchange, shunting;

VENTILATION: artificial, inverse ratio, oxygen tension

(gradients), shunting

OXYGEN: blood levels, gradients, tension.

From the Department of Anaesthesia, National University Hospital, National University of Singapore, Lower Kent Ridge Road, Singapore 0511.

Address correspondence to: Dr. W.A. Tweed, Visiting Professor, Department of Anacsthesia, National University

Hospital, Lower Kent Ridge Road, Singapore 0511. Accepted for publication 10th December, 1990.
La ventilation à ratio inversée (IRV) a été rapportée comme favorisant l'oxygénation par des pressions des voies aériennes plus basses chez les patients en insuffisance respiratoire. Ainsi on a émis l'hypothèse que l'IRV améliore l'échange d'oxygène lors de l'anesthésie. La ventilation avec un ratio conventionnel (CRV) et l'IRV ont été comparés chez 24 patients à bas risque chirurgical qui furent paralysés et dont les poumons ont été ventilés avec de l'airl $\mathrm{O}_{2}$ par un circuit sans réinspiration et un respirateur Siemens 900-C servo. Deur niveaux d'IRV à cycle temporel (I:E ratios de 60/40 et 77/23) ont été incorporés avec des périodes contrôles sur CRV (I:E ratio/35/65). La fraction inspirée d' oxygène, la captation d' $\mathrm{O}_{2}$ et l'élimination du $\mathrm{CO}_{2}$, les gaz sanguins artériels, la ventilation pulmonaire et la mécanique pulmonaire, la fréquence cardiaque et la pression artérielle furent mesurés. A partir de ces données l'espace mort alvéolaire et ventilatoire et quatre indices de tension d'oxygène de l'échange gazeux furent calculés. Lors de l'IRV, la pression moyenne des voies aériennes (mean AWP) augmenta mais il n'y avait aucun changement dans les indices de l'échange d'oxy. gène, la mécanique pulmonaire, la fréquence cardiaque ou la pression artérielle. Le sous-groupe de cet échantillon avec un échange d'oxyène modérément altéré défini par le quart supérieur de la $\mathrm{DO}_{2}(A-a)$, fut examiné séparément avec des résultats similaires. Des modèles multivariés furent testés afin d'identifier les variables qui prédisent l'échange d'oxygène lors du CRV. L'áge du patient fut le seul prédicteur significatif chez tous les modèles. On conclut que l'âge est un déterminant important de l'altération de l'échange pulmonaire d'oxygène lors de l'anesthésie et que l'augmentation de la pression moyenne des voies aériennes par la TC-IRV n'a pas d'effets bénéfiques sur la mécanique pulmonaire ou l'échange gazeux.

Inverse ratio ventilation (IRV) is a method of controlled ventilation in which inspiratory time ( $\mathrm{TI}$ ) occupies more than $50 \%$ of the total respiratory cycle (TT). Two forms of IRV, time cycled (TC-IRV) and pressure controlled (PC-IRV), have been described. In clinical studies TC IRV has improved gas exchange at lower peak inspiratory and end-expiratory pressures in neonates with hyaline 
membrane disease (HMD), ' and in patients with severe adult respiratory distress syndrome (ARDS). ${ }^{2-6}$ With PC-IRV peak inspiratory pressure is limited, the inspiratory waveform is prolonged, and end-expiratory pressure can be controlled. It has also been reported to improve oxygenation in patients with respiratory failure, with no detrimental effects on haemodynamic variables or oxygen delivery. ${ }^{7.8}$

There has been only one reported assessment of IRV during anaesthesia. ${ }^{9}$ In that study Spocrel observed that low frequency IRV with an I:E ratio of up to $4: 1$ provided adequate gas exchange with no adverse effects on blood pressure, heart rate, or electrocardiogram.

Impaired gas exchange is common during general anaesthesia, ${ }^{10}$ and is associated with reduced functional residual capacity (FRC) to below closing capacity, ${ }^{11}$ dependent atelectasis, ${ }^{12.13}$ and increased shunt fraction. ${ }^{10}$ There is no consensus on how these changes are best prevented or treated. ${ }^{14}$ Because IRV has been used with apparent benefit in the treatment of ARDS, we hypothesized that it would prevent or reverse the gas exchange impairment of general anaesthesia. This clinical study was designed, therefore, to compare the effects of TC-IRV and conventional ratio ventilation (CRV) on pulmonary mechanics, gas exchange, and cardiovascular function in a representative sample of low-risk surgical patients, and to select the best model and variables to predict gas exchange during CRV and anaesthesia.

\section{Methods}

The protocol was approved by Departmental and Institutional Ethics Review Committees.

The study sample was 24 post-adolescent ASA physical status I and II patients scheduled for elective orthopaedic operations on the spine or extremities under general tracheal anaesthesia. Routine preanaesthetic workup included history, physical examination and chest radiograph. Patients with a history of recent symptomatic pulmonary disease, abnormal physical or radiological findings or currently smoking more than ten cigarettes per day were excluded. Twenty-one were placed in the supine and three in the prone position for surgery.

Most patients received premedication with lorazepam or midazolam. Anaesthesia was induced with propofol 2 $\mathrm{mg} \cdot \mathrm{kg}^{-1}$, fentanyl 2-3 $\mu \mathrm{g} \cdot \mathrm{kg}^{-1}$, and succinylcholine $1-2 \mathrm{mg} \cdot \mathrm{kg}^{-1}$. After tracheal intubation, anaesthesia was maintaired with a continuous infusion of propofol, 6-10 $\mathrm{mg} \cdot \mathrm{kg}^{-1} \cdot \mathrm{hr}^{-1}$ and intermittent boluses of fentanyl. Muscle paralysis was maintained with either alcuronium $(0.3$ $\left.\mathrm{mg} \cdot \mathrm{kg}^{-1}\right)$ or pancuronium $\left(0.1 \mathrm{mg} \cdot \mathrm{kg}^{-1}\right)$, and controlled intermittent positive pressure ventilation (IPPV) with a Siemens $900-\mathrm{C}$ servo ventilator at a rate of $10 \mathrm{~min}^{-1}$. The anaesthesia circuit was non-rebreathing with a fresh gas mixture of air $/ \mathrm{O}_{2}$ at $12 \mathrm{~L} \cdot \mathrm{min}^{-1}$ and an inspiratory $\mathrm{O}_{2}$ concentration $\left(\mathrm{FIO}_{2}\right)$ of 0.42 . Tidal volume was adjusted so that end-tidal $\mathrm{CO}_{2}$ was between 4.0 and $5.0 \%$.

Three respiratory patterns were studied: a control pattern (CRV) in which $T_{I}$ was set to 0.35 of $T_{T}$, with 0.25 as active inspiration and 0.1 as inspiratory pause, and two patterns of IRV in which T1 was 0.6 and 0.77 , each including an inspiratory pause of 0.1 . The first set of control measurements was made after surgery had begun and a stable state of anaesthesia and ventilation was established; the IRV patterns were introduced in random order and measurements taken after 15 min of ventilation with each; then the IRV was bracketed with a second control.

Airway pressures were recorded from the ventilator, end-tidal $\mathrm{CO}_{2}\left(\mathrm{FeTCO}_{2}\right)$ from a Siemens $\mathrm{CO}_{2}$ Analyzer Model 930 , and pulmonary mechanics (inspiratory and expiratory resistance, end-expiratory pressure and compliance) from a Siemens Pulmonary Mechanics Calculator Model 940.* A Datex Deltatrac Metabolic Monitor was used to measure $\mathrm{O}_{2}$ uptake $\left(\mathrm{V}_{2}\right), \mathrm{CO}_{2}$ elimination $\left(\dot{\mathrm{V}} \mathrm{CO}_{2}\right), \dot{\mathrm{VE}}, \mathrm{FIO}_{2}$, and respiratory exchange ratio (RQ). Metabolic measures were recorded at one-minute intervals, and the final five to seven measures during each period were averaged. At the end of each study period an anaerobic arterial blood sample was drawn from an indwelling radial artery cannula and analyzed immediately in a Nova Stat Profile Blood Gas Analyzer at $37^{\circ} \mathrm{C}$. Heart rate (HR) was recorded from the ECG monitor and blood pressure (BP) by a Dinamap Automatic BP Monitor at three minute intervals. All measuring instruments were appropriately calibrated.

The alveolar $\mathrm{CO}_{2}$ fraction, $\mathrm{FACO}_{2}$, was calculated from the $\mathrm{PaCO}_{2}$ by the method described by Takala and Meriläinen. ${ }^{15}$ Effective alveolar ventilation ( $\dot{\mathrm{V}}_{\mathrm{A}}$, BTPS) was then calculated as $\dot{\mathrm{V}}_{\mathrm{A}}=\dot{\mathrm{V}} \mathrm{CO}_{2} / \mathrm{FACO}_{2}$, physiological dead space ventilation $\left(\dot{V}_{D}, B T P S\right)$ as $\dot{V}_{D}=$ $\dot{V}_{E}-\dot{V}_{A}$, and physiological dead space to tidal volume ratio $(\mathrm{VD} / \mathrm{V} r \mathrm{r})$ as $\dot{\mathrm{V}} \mathrm{D} / \dot{\mathrm{V}} \mathrm{E}$. The alveolar oxygen tension was calculated by the formula adopted by Pappenheimer et al. ${ }^{16}$ :

$$
\begin{aligned}
\mathrm{PAO}_{2}=\mathrm{FIO}_{2}\left(\mathrm{~PB}-\mathrm{PAH}_{2} \mathrm{O}\right)-\underset{\mathrm{PaCO}}{2}\left[\mathrm{FlO}_{2}+\right. \\
\left.\left(1-\mathrm{FlO}_{2}\right) / \mathrm{RQ}\right]
\end{aligned}
$$

Since Singapore is at sea level the barometric pressure $P B$ was assumed to be $760 \mathrm{mmHg}$ and alveolar water vapour partial pressure $\left(\mathrm{PAH}_{2} \mathrm{O}\right)$ to be $47 \mathrm{mmHg}$. During

\footnotetext{
*The following calculations are performed by the Siemens 940 Calculator: lung and chest wall compliance $=$ exp. tidal volume $\div$ (pause press. - end exp. lung press.); end exp. lung press. = cnd cxp. press. + (end. exp. flow $x$ exp. resistance); exp. resistance $=$ (pause press. early exp. press.) $\div$ early exp. flow; insp. resistance $=($ peak press. - pause press.) $\div$ end insp. flow.
} 
TABLE I Control state comparative data of the upper quartile and lower three quartiles for (A-a) DO $\mathrm{D}_{2}$ (Mean (SD))

\begin{tabular}{|c|c|c|c|c|c|}
\hline & age yr & Weight kg & $A S A \|$ & $\mathrm{PaO}_{2} \mathrm{mmH}_{\mathrm{g}}$ & $\mathrm{SaO}_{2} \%$ \\
\hline Upper quartile & $59(10)$ & $69.3(9.8)$ & $5 / 6$ & $104(20)$ & $98.5(1.5)$ \\
\hline Lower 3 quart's & $39(15)$ & $62.4(6.9)$ & $3 / 18$ & $198(31)$ & $99.3(0.9)$ \\
\hline P-value & $<.001$ & NS & $<.01$ & $<.0001$ & $<.01$ \\
\hline \multirow[t]{2}{*}{ Pooled data } & $37(19)$ & $64.2(8.1)$ & $8 / 24$ & $180(49)$ & $99.1(1.1)$ \\
\hline & $(A-a) D_{2} \mathrm{mmHg}_{\mathrm{H}}$ & $V_{D} / V_{T}$ & $\operatorname{PeakAWP} \mathrm{cm} \mathrm{H}_{2} \mathrm{O}$ & $\begin{array}{l}\text { Exp res cm } \mathrm{H}_{2} \mathrm{O} \\
L^{-1} \cdot \mathrm{min}^{-1}\end{array}$ & $B P$ sys $m m H g$ \\
\hline Upper quantile & $157(7)$ & $0.39(0.06)$ & $15(3)$ & $14(5)$ & $130(36)$ \\
\hline Lower 3 quart. & $59(36)$ & $0.30(0.06)$ & $13(2)$ & $11(2)$ & $118(18)$ \\
\hline P-value & & $<0.01$ & $<0.01$ & $<0.0001$ & $<0.05$ \\
\hline Pooled data & $83(33)$ & $0.33(0.06)$ & $13(3)$ & $11(3)$ & $121(24)$ \\
\hline
\end{tabular}

The six subjects in the upper quartile for $(A-a) \mathrm{DO}_{2}$ were compared with the 18 in the lower three quartiles. Variables that were not significantly different by unpaired t test are not shown.

the months of this study the actual low and high mean sea level barometric pressures recorded by the Meteorological Service of Singapore were 1004 and $1016 \mathrm{mbs}$ respectively, and the average was $1010 \mathrm{mbs}$.

Pulmonary gas exchange was assessed by calculating the four indices of gas exchange based on measured $\mathrm{FIO}_{2}$, temperature corrected $\mathrm{PaO}_{2}$, and calculated $\mathrm{PAO}_{2}::^{17}$

1 the alveolar-arterial oxygen tension difference, $(\mathrm{A}-\mathrm{a}) \mathrm{DO}_{2}$,

2 the arterial/alveolar oxygen tension ratio, $\mathrm{PaO}_{2} / \mathrm{PAO}_{2}$,

3 the arterial oxygen tension/inspired oxygen fraction ratio, $\mathrm{PaO}_{2} / \mathrm{FIO}_{2}$,

4 and the respiratory index (RI), (A-a) $\mathrm{DO}_{2} / \mathrm{PaO}_{2}$.

The 24 subjects were divided into quartiles reflecting oxygen exchange impairment, using the values for (A-a) $\mathrm{DO}_{2}$ of the first control period; and demographic and physiological variables for the upper and lower three quartiles were compared by unpaired t tests. Measured and calculated variables for the two periods of IRV and two periods of CRV were compared by ANOVA and Least Significant Differences tests. Multivariate models were developed for each of the oxygen exchange indices and these were examined by Stepwise Variable Selection and Multiple Regression Analysis (Statsgraphics) to identify significant predictor variables for gas exchange during CRV.

\section{Results}

The subjects for this study comprised a representative sample of low risk, post-adolescent elective surgical patients in Singapore (Table I). Their age range was $14-71 \mathrm{yr}$, and body weight range $48-82 \mathrm{~kg}$. Three of the eight ASA physical status II patients and one ASA I patient smoked less than ten cigarettes per day. In racial diversity the sample was representative of the population of Singapore, including Chinese, Indians, and Malays.

The sample was divided into quartiles, based on the first control state $(A-a) D_{2}$, and the upper quartile $\left[(A-a) D_{2}=134-166\right]$ was compared with the lower three quartiles [(A-a)DO $\left.\mathrm{DO}_{2}=5-119\right]$ (Table I). The upper quartile were older, predominantly ASA II, and had significantly worse pulmonary function.

The four study periods were compared by ANOVA. The upper quartile and lower three quartiles were examined separately, but since the results were identical only the pooled data are presented in Table II. There were also no differences between the three subjects studied in the prone position and the 21 studied supine. Differences among the four periods were statistically significant for mean airway pressure (mean AWP), respiratory exchange ratio (RQ), and $V_{D} / V_{T}$. There were no significant differences in pulmonary mechanics, arterial blood gases, effective alveolar ventilation, the indices of oxygen exchange, $\mathrm{HR}$ or $\mathrm{BP}$. End-expiratory pressure was less than $\mathrm{I} \mathrm{cm} \mathrm{H}_{2} \mathrm{O}$ in all cases.

Stepwise variable selection and multiple regression analysis were used to identify predictors of oxygen exchange during CRV, using data from the first control period. Independent variables tested in the predictive models were mean AWP, tidal volume, body weight, age, ASA class, and $V_{D} / V_{T}$. Comparable models were obtained with all four oxygen exchange indices, with age being the only variable that was both statistically and clinically significant in all models (Table III). Although tidal volume and VD/VT were weakly significant in some models, they did not substantially improve the predictive value of any, and $\mathrm{VD} / \mathrm{VT}$ was cross-correlated with age. Since $\mathrm{VT}_{\mathrm{T}}$ was set to maintain a preselected $\mathrm{FETCO}_{2}$, it was strongly related to $\dot{\mathrm{V}} \mathrm{CO}_{2}$ and body weight $\left(r^{2}=0.84\right.$, $P=0.0000$ ). 
TABLE II Inverse ratio ventilation: pooled data (Mean (SEM), $n=24$ )

\begin{tabular}{|c|c|c|c|c|c|}
\hline & $35: 65$ & $60: 40$ & $77: 23$ & $35: 65$ & \\
\hline \multicolumn{6}{|l|}{ Controlled variables } \\
\hline VT ml & $553(18)$ & $\$ 50(20)$ & $559(20)$ & $558(16)$ & \\
\hline FET $\mathrm{CO}_{2} \%$ & $4.2(0.1)$ & $4.2(0.2)$ & $4.2(0.2)$ & $4.1(0.2)$ & \\
\hline $\mathrm{FlO}_{2}$ & $0.42(0.01)$ & $0.42(0.01)$ & $0.42(0.01)$ & $0.42(0.01)$ & \\
\hline $\mathrm{FAO}_{2} \mathrm{mmHg}$ & $263(4)$ & $262(4)$ & 261 (5) & $258(4)$ & \\
\hline Temp. ${ }^{\circ} \mathrm{C}$ & $35.8(0.1)$ & $35.7(0.1)$ & $35.5(0.1)$ & $35.5(0.1)$ & \\
\hline \multicolumn{6}{|l|}{ Cardiovascular } \\
\hline HR & $76(2)$ & 79 (3) & $79(3)$ & $80(3)$ & \\
\hline Syst BP mmHg & $118(5)$ & $122(6)$ & $124(6)$ & 119 (4) & \\
\hline Diast BP mmHg & $72(3)$ & 75 (4) & 75 (3) & $72(2)$ & \\
\hline \multicolumn{6}{|l|}{ Pulmonary Mechanics } \\
\hline Peak AWP $\mathrm{cm} \mathrm{H}_{2} \mathrm{O}$ & $13.3(0.5)$ & $12.2(0.5)$ & $13.2(0.5)$ & $13.9(0.5)$ & \\
\hline Mean AWP cm H $\mathrm{H}_{2} \mathrm{O}$ & $3.0(0.2)$ & $4.7(0.3)^{*}$ & $7.0(0.3)^{*}$ & $3.2(0.2)$ & $P<0.00001$ \\
\hline Exp Res $\mathrm{cm} \mathrm{H}_{2} \mathrm{O} \cdot \mathrm{L}^{-1} \cdot \min ^{-1}$ & $11.0(0.4)$ & $11.2(0.6)$ & $11.5(0.6)$ & $11.7(0.9)$ & \\
\hline Comp. $\mathrm{ml} \cdot \mathrm{cm} \mathrm{H} \mathrm{H}_{2} \mathrm{O}^{-1}$ & $49(2)$ & $49(2)$ & $52(3)$ & $48(2)$ & \\
\hline \multicolumn{6}{|l|}{ Metabolic rates } \\
\hline$\dot{\mathrm{V}} \mathrm{CO}_{2} \mathrm{ml} \cdot \min ^{-1}$ & $151(5)$ & $148 \quad(5)$ & $147(5)$ & $146(6)$ & \\
\hline $\mathrm{VO}_{2} \mathrm{ml} \cdot \min ^{-1}$ & $164(6)$ & $163(6)$ & $167(7)$ & $171(6)$ & \\
\hline Resp exch ratio & $0.93(0.02)$ & $0.91(0.01)$ & $0.89(0.01)$ & $0.85(0.01)^{*}$ & $P<0.01$ \\
\hline \multicolumn{6}{|l|}{ Arterial blood gases } \\
\hline $\mathrm{pH}$ & $7.42(0.01)$ & $7.43(0.01)$ & $7.43(0.01)$ & $7.41(0.01)$ & \\
\hline $\mathrm{PCO}_{2} \mathrm{mmHg}-37^{\circ} \mathrm{C}$ & $38.0(1.2)$ & $37.1(1.2)$ & $36.7(1.2)$ & $38.8(1.1)$ & \\
\hline $\mathrm{PO}_{2} \mathrm{mmHg}$ & $180(10)$ & $172(11)$ & $177(11)$ & $169(10)$ & \\
\hline Bicarb $\mathrm{mEq} \cdot \mathrm{L}^{-1}$ & $24.3(0.3)$ & $24.4(0.4)$ & $24.2(0.4)$ & $24.0(0.3)$ & \\
\hline \multicolumn{6}{|c|}{ Alveolar ventilation and gas exchange } \\
\hline$\dot{\mathrm{V}}_{\mathrm{A}} \mathrm{ml} \cdot \mathrm{kg}^{-1} \cdot \min ^{-1}$ & $58.6(2.7)$ & $58.7(2.9)$ & $57.8(2.2)$ & $54.5(1.8)$ & \\
\hline$V_{D} / V_{T}$ & $0.33(0.01)$ & $0.32(0.01)$ & $0.33(0.01)$ & $0.37(0.01)^{*}$ & $P<0.05$ \\
\hline$(\mathrm{A}-\mathrm{a}) \mathrm{DO}_{2}$ & $83 \quad(11)$ & $91 \quad(12)$ & $84 \quad(13)$ & $88 \quad(12)$ & \\
\hline $\mathrm{PaO}_{2} / \mathrm{PAO}_{2}$ & $0.69(0.04)$ & $0.66(0.04)$ & $0.69(0.05)$ & $0.66(0.04)$ & \\
\hline $\mathrm{PaO}_{2} / \mathrm{FlO}_{2}$ & $428(26)$ & $412(28)$ & $428(30)$ & $409(28)$ & \\
\hline Resp index & $0.61(0.12)$ & $0.70(0.13)$ & $0.64(0.14)$ & $0.71(0.14)$ & \\
\hline
\end{tabular}

Comparison of the four study periods using pooled data for 24 subjects. Statistical analysis was by one-way ANOVA and LSD tests. Abbreviations are defined in the text.

*Indicates that a group is significantly different from the first control at $P<0.05$.

\section{Discussion}

In this sample of patients the only effect of IRV at $I: E$ ratios of approximately $2: 1$ and 3:1 was to increase mean AWP. There were no clinically significant effects on other measures of pulmonary or cardiovascular function. In particular there was no improvement in oxygen exchange over that measured in the control state, even in patients with substantial (A-a) gradients for $\mathrm{O}_{2}$. Although cardiac output and physiological shunt fraction were not directly measured, the lack of change in other variables provides indirect evidence that they too were unaffected.
One might argue that the lack of benefit to gas exchange was due to insufficient time at each level of IRV. Patients with ARDS had $30 \mathrm{~min}$ to several hours of IRV before improvements in oxygenation were observed. ${ }^{2,5,8}$ However, our patients had no active lung disease and normal lung compliance. Since continuous positive pressure ventilation (CPPV) improved gas exchange within $15 \mathrm{~min}$ in similar patients, ${ }^{18}$ and manual sighs resulted in immediate improvement in both compliance and oxygenation, ${ }^{19,20}$ we believe that we allowed sufficient time to demonstrate an effect of IRV. 
TABLE III Statistically significant predictors of oxygen exchange and tidal volume

\begin{tabular}{|c|c|c|c|}
\hline $\begin{array}{l}\text { Dependen } \\
\text { variable }\end{array}$ & $\begin{array}{l}\text { Independent } \\
\text { variable.s }\end{array}$ & $\begin{array}{l}\text { Correlation } \\
\text { coefficient }\end{array}$ & P-value \\
\hline $\begin{array}{l}(\mathrm{A}-\mathrm{a}) \mathrm{DO}_{2} \\
\mathrm{PaO}_{2} / \mathrm{PAO}_{2} \\
\mathrm{PaO}_{2} / \mathrm{FIO}_{2} \\
\mathrm{RI}\end{array}$ & Age & $0.55-0.57$ & $<0.005$ \\
\hline$V_{T}$ & $\begin{array}{l}\dot{\mathrm{V}} \mathrm{CO}_{2} \\
\text { Wcight }\end{array}$ & 0.93 & $\begin{array}{l}<0.002 \\
<0.0000\end{array}$ \\
\hline
\end{tabular}

Significant predictor variables for determinants of oxygen exchange and tidal volume. Analysis was by Statsgraphics, stepwise variable selection and multiple regression analysis.

The other statistically significant changes observed were a decrease in the $R Q$, and an increase in $V D / V T$ in period four (the repeat control). As these patients' lungs were moderately hyperventilated the decrease in $\mathrm{RQ}$ probably represents adaptation of the body $\mathrm{CO}_{2}$ stores. Twenty to $120 \mathrm{~min}$ are required to reach a new stable level after a change in ventilation. ${ }^{21}$ Since the Deltatrac measures pulmonary gas flux in one-minute epochs, and the $R Q$ was used only to calculate simultaneous $\mathrm{PAO}_{2}$, these changes are too gradual to affect the accuracy of the gas exchange estimations. The apparent increase in $\mathrm{VD}_{\mathrm{D}} \mathrm{VT}_{\mathrm{T}}$ in period four probably represents transient instability of $\mathrm{PCO}_{2}$ associated with tourniquet release in some of the subjects.

During conventional ventilation impaired oxygen exchange was significantly correlated with increasing age, accounting for about $32 \%$ of the variation in arterial oxygenation. The effect of age is well known and is possibly due to loss of lung elasticity and a shift of closing capacity into the $V_{T}$ range during anaesthesia. ${ }^{22}$ Tidal volume did not vary independently, but was determined by $\dot{\mathrm{V}} \mathrm{CO}_{2}$ and body weight; and $\mathrm{FIO}_{2}$ was constant. Although $\mathrm{VD} / \mathrm{VT}_{\mathrm{T}}$ was significant by univariate analysis, it was strongly cross-correlated with age, and did not improve the multivariate models. The ASA classification was non-specific and also strongly related to age. No patient was grossly obese. Further examination of these and other predictor variables will require controlled studies.

Computer models ${ }^{23-25}$ and clinical studies ${ }^{18,26}$ have shown that the oxygen tension-based indices of gas exchange do not reliably predict physiologic shunt fraction (Q $\dot{\mathrm{Q}} / \dot{\mathrm{Q} T}$ ), particularly when $\mathrm{FIO}_{2}$ varies, $\dot{\mathrm{Q}} \mathrm{s} / \dot{\mathrm{Q}} \mathrm{T}$ is large, or cardiac output is low. In the present studies, however, $\mathrm{FIO}_{2}$ was held constant at 0.42 and the worst case $\dot{Q} \mathrm{~s} / \dot{Q} \mathrm{~T}$ would not have exceeded $15 \%$. Although cardiac output was not directly measured, there were no changes in $\mathrm{HR}, \mathrm{BP}$, or $\mathrm{VD} / \mathrm{VT}_{\mathrm{T}}$ that would suggest a marked decrease. Since $\mathrm{SaO}_{2}$, measured by continuous pulse oximetry, was always near $100 \%$, changes in $\mathrm{PaO}_{2}$ would in most cases directly reflect changes in content. For these reasons we believe that within the boundaries of this study stability of the gas exchange indices during IRV indicates stability of Q́s/Q்T.

Although pulmonary gas exchange deteriorates during general anaesthesia in older or obese patients, cigarette smokers, and those with pre-existing lung disease, in young healthy non-smokers the impairment is minimal. ${ }^{27}$ Functional residual capacity and total pulmonary compliance are reduced with the onset of general anaesthesia, and changes in the recoil pressures of the lung and particularly the chest wall appear to be primary mechanisms. ${ }^{28}$ Altered mechanics of the diaphragm in the horizontal anaesthetized patient probably plays a crucial role. $^{29}$

An increase in the physiological shunt fraction may be due to true shunting through dependent atelectatic areas or an increase in the volume of regions with very low $\dot{V} / \dot{Q}$ ratios. Hedenstierna ef al. have demonstrated by CT scanning the development of atelectasis. ${ }^{12.13 .30}$ Dueck $e t$ al. have shown that physiological shunting occurs when FRC decreases below closing capacity. ${ }^{11}$

The most effective means to prevent or reverse the gas exchange defect remains elusive. Proposed measures include manual sighs, high tidal volume ventilation, positive end-expiratory pressure (PEEP), and continuous positive pressure ventilation (CPPV). This is the first study to examine IRV. Manual sighs temporarily restore oxygenation and compliance, but must be repeated frequently. ${ }^{19,20}$ High VT ventilation was studied in both $\operatorname{dogs}^{31}$ and humans. ${ }^{20}$ In anaesthetized dogs a VT of $25 \mathrm{ml} \cdot \mathrm{kg}^{-1}\left(\mathrm{PaCO}_{2}=21 \mathrm{mmHg}\right)$ was required to prevent deterioration of physiological shunt. In a clinical study by the same investigators $\mathrm{PaO}_{2}$ and compliance decreased during constant volume ventilation, but less in patients who were hyperventilated. Both compliance and oxygenation were restored by manual sighs. However, they did not calculate indices of gas exchange and it is uncertain to what extent changing $\mathrm{PaCO}_{2}, \mathrm{RQ}$, and $\mathrm{PAO}_{2}$ may explain their results. Visick ef al..$^{32}$ compared small tidal volumes $\left(5 \mathrm{ml} \cdot \mathrm{kg}^{-1}\right)$ with and without $\mathrm{CPP}(10 \mathrm{~cm}$ $\mathrm{H}_{2} \mathrm{O}$ ) with large tidal volumes $\left(15 \mathrm{ml} \cdot \mathrm{kg}^{-1}\right)$. With large $V_{\mathrm{T}}$ there was increased compliance and decreased $V_{\mathrm{D}} / \mathrm{V}_{\mathrm{T}}$, but no difference in mean (A-a) $\mathrm{DO}_{2}$. Only when large $V_{T}$ or CPP replaced small $\mathrm{Vr}$ was $(\mathrm{A}-\mathrm{a}) \mathrm{DO}_{2}$ improved, suggesting that the order of changes was important. Thus deliberate hyperventilation with large tidal volumes, though commonly practised during anaesthesia, is of uncertain benefit. Mixed results have also been reported with PEEP and CPPV. Improved gas exchange has been observed $;^{18}$ but in other studies the decrease in shunt was 
counterbalanced by a decrease in cardiac output, resulting in no change in (A-a) $\mathrm{DO}_{2}{ }^{33}$

The putative beneficial effect of IRV in respiratory failure may be due to the respiratory waveform or airway pressures. In neonates with severe lung disease, ventilated with various I:E ratios and airway pressure waves, optimal oxygenation was achieved with the I:E ratio and pressure wave combination that produced the highest mean AWP. ${ }^{34}$ As evidence against a predominant effect of respiratory waveform, oxygenation in a dog model of acute respiratory failure was better with conventional ventilation and PEEP than with IRV at the same mean AWP. ${ }^{35}$ Others have suggested that inadequate expiratory time leads to air trapping and occult positive endexpiratory pressure or "auto-PEEP". ${ }^{36}$ This is inherent in the PC-IRV mode, where PEEP is adjustable.

In our patients, with both mild and moderate impairment of gas exchange, oxygenation was not related to mean AWP. At the same time there was no auto-PEEP and no increase in compliance; thus end-expiratory lung volume was probably unchanged. Although the lung dysfunction of anaesthesia may be different from that of respiratory failure, some of the mechanisms, e.g., physiological shunting, appear to be similar. In conjunction with the studies reviewed above, these results suggest that increased airway pressure must be sustained throughout the respiratory cycle in order to increase FRC and to recruit collapsed alveoli, thereby improving oxygen exchange.

In conclusion we have shown that, compared with CRV, IRV had no beneficial effect on mild to moderately impaired gas exchange during anaesthesia. On the other hand no detrimental effects on respiratory or circulatory function were observed with $\mathrm{I}: \mathrm{E}$ ratios up to $3: 1$. Patient age was a significant determinant of oxygen exchange during CRV, but mean AWP was not. Although TC-IRV increased mean AWP, it did not improve pulmonary function or gas exchange.

\section{Acknowledgements}

We gratefully acknowledge the support of the National University of Singapore, the National University Hospital, the surgeons of the Department of Orthopaedics, and Siemens (Pte) Lid of Singapore for the loan of the ventilator and accessories.

\section{References}

1 Spahr RC, Klein MD, Brown DR, MacDonald HM, Holzman IR. Hyaline membrane disease. A controlled study of inspiratory to expiratory ratio in its management by ventilator. Am J Dis Child 1980; 134: 373-6.
2 Ravizza AG, Carugo D, Cerchiari EL et al. Inverse ratio and conventional ventilation: comparison of the respiratory effects (Abs). Anesthesiology 1983; 59: A523.

3 Lamp KM, Gelb AW, Wexler HR, Stein J, Spoerel WE. Assessment of inversed ratio ventilation in the adult respiratory distress syndrome (Abs). Anesth Analg 1984; 63: 241.

4 Gurevitch MJ, Van Dyke J, Young ES, Jackson K. Improved oxygenation and lower peak airway pressure in severe adult respiratory distress syndrome. Treatment with inverse ratio ventilation. Chest 1986; 89: 211-13.

5 Greaves TH, Cramolini GM, Walker DH et al. Inverse ratio ventilation in a 6 year-old with severe post traumatic adult respiratory distress syndrome. Crit Care Med 1989; 17: 588-9.

6 Enderson BL, Farnham W, Langdon JR. Inversc I:E ratio ventilation can improve oxygenation in adult respiratory distress syndrome (Abs). Crit Care Med 1989; 17: S152.

7 Tharratt RS, Allen RP, Alberison ET. Pressure controlled inverse ratio ventilation in severe adult respiratory failure. Chest 1988; 94: 755-62.

8 Abraham $E$, Yoshihara $G$. Cardiorespiratory effects of pressure controlled inverse ratio ventilation in severe respiratory failure. Chest 1989; 96: 1356-9.

9 Spoerel WE. Low frequency ventilation. The Bain breathing circuit with the Automatic-Vent and the Minivent. Anaesthesia 1980; 35: 1087-93.

10 Nunn JF. Anaesthesia and pulmonary gas exchange. In: Covino BG et al. (Eds.). Effects of Anesthesia. Bethesda, Maryland: American Physiological Socicty, 1985: 137-47.

11 Dueck R, Prutow RJ, Davies NJH, Clausen JL, Davidson $T M$. The lung volume at which shunting occurs with inhalation anaesthesia. Anesthesiology 1988; 69: 854-61.

12 Gunnarsson L, Strandberg A, Brismar B et al. Atclectasis and gas exchange impairment during cnflurane/nitrous oxide anaesthesia. Acta Anaesthesiol Scand 1989; 33: 629-37.

13 Klingstedt $C$, Hedenstierna $G$, Lundquist $H$ et al. The influence of body position and differential ventilation on lung dimensions and atalectasis formation in anaesthetized man. Acta Anaesthesiol Scand 1990; 34: 315-22.

14 Schwieger I, Gamulin Z, Suter PM. Lung function during anaesthesia and respiratory insufficiency in the postoperative period: physiological and clinical implications. Acta Anacsthesiol Scand 1989; 33: 527-34.

15 Takala J, Meriläinen P. Handbook of gas exchange and indirect calorimetry. Document No. 876710. Datex/ Instrumentarium Corp., P.O. Box 357, SF-00101 Helsinki, Finland.

16 Pappenheimer JR, Comroe JH, Cournand A et al. Standardization of definitions and symbols in respiratory physiology. Fed Proc 1950; 9: 602-5. 
17 Herrick IA, Champion LK, Froese AB. A clinical comparison of indices of pulmonary gas exchange with changes in the inspired oxygen concentration. Can J Anacsth 1990; 37: $69-76$

18 Wyche MQ, Teichner RL, Kallos $T$, Marshall BE. Smith TC. Effects of continuous positive pressure breathing on functional residual capacity and arterial oxygenation during intra-abdominal operations. Anesthesiology 1973; 38: 68-74.

19 Egbert $L D$, Laver $M B$, Bendixen $H H$. Intermittent deep breaths and compliance during anesthesia in man. Anesthesiology 1963; 24: 57-60.

20 Bendixen $H H$, Hedley-Whyte $M B$, Laver MB. Impaired oxygenation in surgical paticnts during general anesthesia with controlled ventilation. A Concept of Atelectasis. New Engl J Med 1963; 269: 991-6.

21 Henneberg $S$, Soderberg $D$. Groth $T$, Sijernstrom $H$, Wiklund $L$. Carbon dioxide production during mechanical ventilation. Crit Care Med 1987; 15:8-13.

22 Don $H F$, Wahba $W M$, Craig $D B$. Airway closurc, gas trapping, and functional residual capacity during anaesthesia. Anesthesiology 1972; 36: 533-9.

23 Doyle JD. Arterial/alveolar oxygen tension ratio: a critical appraisal. Can Anaesth Soc J 1986; 33: 471-4.

24 Rasanen J, Downs JB, Malec DJ, Oates K. Oxygen tensions and oxyhemoglobin saturations in the assessment of pulmonary gas exchange. Crit Care Med 1987; 15: 1058-61.

25 Zetterstrom $H$. Assessment of the efficiency of pulmonary oxygenation. The choice of oxygenation index. Acta Anacsthesiol Scand 1988; 32: 579-84.

26 Cane DR, Shapiro BA, Templin $R$, Walther $K$. Unreliability of oxygen tension-based indices in reflecting intrapulmonary shunting in critically ill patients. Crit Care Med 1988; 16: 1243-5.

27 Rehder K, Knopp TJ, Sessler AD, Didier EP. Ventilationperfusion relationships in young healthy awake and anesthetized-paralyzed man. J Appl Physiol 1979; 47: 745-53.

28 Rehder $K$. Anesthesia and the mechanics of respiration. In: Covino BG et al. (Eds.). Effects of Anesthesia. Bcthesda, Maryland: American Physiological Society $1985 ; 91-106$.

29 Froese $A B$. Effects of anesthesia and paralysis on the chest wall. In: Covino BG et al. (Eds.). Effects of anesthesia. Bethesda, Maryland: American Physiological Society 1985: 107-20.

30 Brisma $B$, Hedenstierna $G$, Lundquist $H$ et al. Pulmonary densities during anesthesia with muscular relaxation - a proposal of atelectasis. Anesthesiology 1985; 62: 422-8.
31 Hedley-Whyte $J$, Laver $M B$, Bendixen $H H$. Effects of changes in tidal ventilation on physiologic shunting Am J Physiol 1964; 206: 891-7.

32 Visick WD, Fairley $H B$, Hickey RF. The cffects of tidal volume and end-expiratory pressure on pulmonary gas exchange during anesthesia. Anesthesiology 1973; 39: 285-90.

33 Bindslev LG, Hedenstierna G, Santesson J, Goulieb I, Carvallhas $A$. Ventilation-perfusion distribution during inhalation anaesthesia. Acta Anaesthesiol Scand 1981; 25: $360-71$.

34 Boros SJ. Variations in inspiratory:expiratory ratio and airway pressure wave form during mechanical ventilation: the significance of mean airway pressure. J Pediatr 1979; 94: 114-7.

35 Berman LS, Downs JB, Van Eeden A, Delhagen D. Inspiration:expiration ratio. Is mean airway pressure the difference? Crit Care Med 1981; 9: 775-7.

36 Duncan $S R$, Rizk NW, Raffin TA. Inverse ratio ventilation. PEEP in disguise? (Editorial) Chest 1987; 92: 390-2. 